Revista Eletrônica de Direito Processual - REDP. Volume 16. Julho a dezembro de 2015

Periódico Semestral da Pós-Graduação Stricto Sensu em Direito Processual da UERJ

Patrono: José Carlos Barbosa Moreira. ISSN 1982-7636. pp. 664-683 http://www.e-publicacoes.uerj.br/index.php/redp/index

\title{
A FLEXIBILIZAÇÃO DO PROCEDIMENTO E SUA ABORDAGEM NA \\ TRAMITAÇÃO LEGISLATIVA DO NOVO CÓDIGO DE PROCESSO CIVIL ${ }^{1}$
}

\section{THE PROCEDURAL FLEXIBILITY AND ITS APPROACH IN THE LEGISLATIVE PROCEDURE OF THE NEW BRAZILIAN CIVIL PROCEDURE CODE}

Taynara Tiemi Ono

Mestranda em Direito pela Universidade de Brasília/UnB.

Advogada.

taynara.ono@gmail.com

RESUMO: Este artigo descreve o tratamento legislativo atribuído ao instituto da Flexibilização Procedimental durante a tramitação do Novo Código de Processo Civil (20102015) nas casas legislativas brasileiras. O Código de Processo Civil de 1973 delineia minuciosamente os atos a serem realizados ao longo do processo e sustenta a rigidez do procedimento. O reflexo prático dessa rigidez é a impossibilidade de mudança ou de adaptação dos atos processuais, excetuando-se a ocorrência de alterações mínimas e apenas em situações especiais. O Novo CPC (Lei 13.105/2015) trouxe tentativas de remediar e solucionar essa incompatibilidade. Essas mudanças passaram a integrar o texto da lei após diferentes discussões acerca da matéria da Flexibilização Procedimental, desde a proposição do Anteprojeto até sua aprovação no Senado Federal e na Câmara dos Deputados.

PALAVRAS-CHAVE: Flexibilização procedimental; Código de Processo Civil de 1973; Novo Código de Processo Civil brasileiro; Processo Legislativo; Abordagens.

ABSTRACT: This essay describes the legislative approaches of Procedural Flexibility throughout the legislative process (2010-2015) concerning the new Code of Civil Procedure of Brazil. The description the Brazilian 1973 Civil Procedure Code gives of the acts to be performed in each process is exhaustive and upholds the rigidity of procedure. This thoroughness makes it impossible to change or adapt procedural acts, except in special situations. The new Civil Procedure Code (Statutory Law $§ 13.105$ (2015)) has attempted to

\footnotetext{
${ }^{1}$ Artigo recebido em 19/09/15 e aprovado em 27/11/2015.
} 
Revista Eletrônica de Direito Processual - REDP. Volume 16. Julho a dezembro de 2015

Periódico Semestral da Pós-Graduação Stricto Sensu em Direito Processual da UERJ

Patrono: José Carlos Barbosa Moreira. ISSN 1982-7636. pp. 664-683 http://www.e-publicacoes.uerj.br/index.php/redp/index

solve this incompatibility. The changes brought by the new Code originated from different discussions on the subject of Procedural Flexibility, spanning from the production of the draft bill to its passing on the House of Representatives and on the Senate.

KEYWORDS: Procedural Flexibility; 1973 Code of Civil Procedure; new Code of Civil Procedure of Brazil; Legislative procedure; Approaches.

SUMÁRIO: 1. Introdução - 2. O procedimento à luz do Código de Processo Civil de 1973; 2.1. O procedimento - 3. A flexibilização procedimental na tramitação legislativa do novo código de processo civil; 3.1. As novidades apresentadas no anteprojeto do novo código de processo civil; 3.2. A tramitação do projeto no Senado Federal; 3.3. O substitutivo apresentado pela Câmara dos Deputados - 4. A flexibilização no novo Código de Processo Civil - 5. Conclusão - Referências bibliográficas.

\section{INTRODUÇÃO}

O procedimento representa o aspecto dinâmico do processo ao estabelecer a maneira como os diferentes atos processuais se relacionarão até que se atinja seu objetivo final, o qual "pode ser uma sentença de mérito ou terminativa, a apuração do quantum debeatur (liquidação de sentença), a satisfação do direito (processo de execução) ou a obtenção de uma garantia (processo cautelar)"”2.

O Código de Processo Civil de 1973 e legislações extravagantes sistematizam variados tipos de procedimentos, que podem vir a ser adotados a depender do tipo da demanda apresentada pelo jurisdicionado. A existência de uma multiplicidade de procedimentos, analisadas conjuntamente com a natureza da prestação jurisdicional pretendida, tem por escopo conferir maior efetividade às regras procedimentais, como por exemplo aquelas que definem os prazos e o modo como determinados atos serão realizados. De modo geral, a prática dos atos processuais submete-se às formalidades impostas pelo código e varia de acordo com o rito processual selecionado.

O legislador, visando a tornar mais eficiente a atividade jurisdicional em termos de previsibilidade e segurança jurídica, sem contudo ignorar totalmente as diferentes

\footnotetext{
${ }^{2}$ GAJARDONI, Fernando da Fonseca. Flexibilidade procedimental: um novo enfoque para o estudo do procedimento em matéria processual. Tese de doutorado em Direito. USP/São Paulo, 2006, p. 81.
} 
Revista Eletrônica de Direito Processual - REDP. Volume 16. Julho a dezembro de 2015

Periódico Semestral da Pós-Graduação Stricto Sensu em Direito Processual da UERJ

Patrono: José Carlos Barbosa Moreira. ISSN 1982-7636. pp. 664-683 http://www.e-publicacoes.uerj.br/index.php/redp/index

características das demandas submetidas ao judiciário, definiu alguns modelos rígidos de procedimentos regidos por regras específicas. Determinada causa seguiria determinado rito caso possuísse as características definidas pela lei processual que as enquadrassem no referido procedimento. Tais critérios podem estar relacionados ao valor da causa, à espécie do direito material a ser tutelado, ao número de litigantes, etc. Buscou-se, em certa medida, considerar os aspectos subjetivos mais evidentes dos casos concretos.

Entretanto, pode-se notar a incapacidade do legislador de prever todas as formas e situações em que uma lei vai ser aplicada. Assim, uma atividade legislativa que realmente leve em consideração a subjetividade na aplicação fática de diplomas normativos deve ter consciência de suas fraquezas antes de criar um sistema e saber que, muitas vezes, precisará criar regras gerais, uma vez que, como já dito, é impossível definir minuciosamente situações hipotéticas até exaurir um tema. Portanto, apesar de o legislador ter considerado a diversidade das demandas ao tentar agrupá-las, a partir de critérios legalmente estabelecidos, vinculando-as a ritos processuais (ou procedimento) específicos, a sua atuação mostra-se insuficiente para abarcar a complexidade inerente às relações sociais, o que, em termos práticos, pode levar a um processamento ineficaz do feito.

Por esse motivo e devido à atualidade da tramitação legislativa do Novo Código de Processo Civil, a temática da flexibilização procedimental ganhou maior relevância e passou recentemente a suscitar debates e questionamentos acerca dos possíveis efeitos jurídicos e práticos da implementação de tal flexibilização no sistema processual brasileiro. Para melhor se abordar o assunto, é importante compreender o funcionamento do sistema processual vigente, as mudanças do CPC cogitadas nas casas legislativas e o modelo de flexibilização inserido no Novo Código de Processo Civil. Tais explanações serão apresentadas nos tópicos seguintes.

Por fim, importa ressaltar que o foco deste trabalho não voltou-se propriamente para a perspectiva da dogmática jurídica em que há, preponderantemente, uma preocupação prática de se compreender o direito enquanto norma e, portanto, voltada para a definição de critérios de aplicação de regras jurídicas aos casos concretos ${ }^{3}$. O maior interesse deste estudo é o fornecimento de dados e questionamentos os quais servirão de subsídio para reflexões,

\footnotetext{
${ }^{3}$ COSTA, Alexandre Araújo. Introdução ao direito: uma perspectiva zetética das ciências jurídicas. Porto Alegre : Sergio Antonio Fabris Editor, 2001, p. 171.
} 
Revista Eletrônica de Direito Processual - REDP. Volume 16. Julho a dezembro de 2015

Periódico Semestral da Pós-Graduação Stricto Sensu em Direito Processual da UERJ

Patrono: José Carlos Barbosa Moreira. ISSN 1982-7636. pp. 664-683 http://www.e-publicacoes.uerj.br/index.php/redp/index

seja ela doutrinária, legislativa ou jurisprudencial, acerca de um aspecto da realidade processual brasileira.

\section{O PROCEDIMENTO À LUZ DO CÓDIGO DE PROCESSO CIVIL DE 1973}

O Código de Processo Civil vigente disciplina minuciosamente os atos do processo, sendo poucas as normas de caráter geral presentes na lei relacionadas à forma dos atos processuais $^{4}$. Aliado a isso, o rigor formal na determinação da ordem dos atos e na distribuição dos ônus e deveres às partes tem sido reconhecido, por parte da doutrina, como essenciais ao incremento da eficiência e da segurança do processo ${ }^{5}$. Ademais, tal necessidade de formas legalmente pré-estabelecidas também associa-se a uma preocupação com a estruturação e a organização interna do processo, responsáveis por emprestar previsibilidade ao procedimento $^{6}$.

Desse modo, buscou o legislador, por intermédio do Código do Processo Civil de 1973, submeter os atos processuais a normas que descrevem, detalhadamente, a forma como esses deverão se manifestar ao longo do processo. Concomitantemente, o legislador destacou a importância da instrumentalidade de tais regras ao considerar como fundamental o cumprimento da finalidade essencial que os atos visam a alcançar no processo.

Não obstante o art. 154 do CPC $/ 1973^{7}$ disponha sobre o princípio da liberdade das formas, ao prever a independência formal dos atos e termos processuais quando estes não forem exigidos em lei, este dispositivo encontra restrições à sua aplicação prática uma vez que a quase totalidade dos atos já se situam expressamente dispostos em lei. Tal regra tem a função preponderante de encerrar o sistema, "pois apenas estabelece o princípio da liberdade

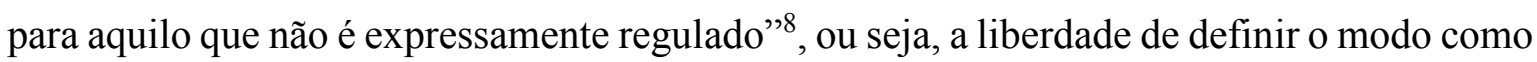
uma demanda será processada está atrelada à inexistência de exigência legal, o que ocorre apenas excepcionalmente em nosso diploma normativo processual.

\footnotetext{
${ }^{4}$ LIEBMAN, Enrico Tullio. Manual de direito processual civil. Vol. 1. 2 ed. Tradução e notas de Cândido Rangel Dinamarco. Rio de Janeiro, 1985, p. 230.

${ }_{5}^{5}$ OLIVEIRA, Carlos Alberto Alvaro de. Do formalismo no processo civil. 4 ed. São Paulo: Saraiva, 2010, p. 153-155.

${ }^{6}$ OLIVEIRA, Carlos Alberto Alvaro de. Do formalismo no processo civil. 4 ed. São Paulo: Saraiva, 2010, p. 285.

${ }^{7}$ Art. 154. Os atos e termos processuais não dependem de forma determinada senão quando a lei expressamente a exigir, reputando-se válidos os que, realizados de outro modo, Ihe preencham a finalidade essencial.

${ }^{8}$ LIEBMAN, Enrico Tullio. Manual de direito processual civil. Vol. 1. 2 ed. Tradução e notas de Cândido Rangel Dinamarco. Rio de Janeiro, 1985, p. 230.
} 
Revista Eletrônica de Direito Processual - REDP. Volume 16. Julho a dezembro de 2015

Periódico Semestral da Pós-Graduação Stricto Sensu em Direito Processual da UERJ

Patrono: José Carlos Barbosa Moreira. ISSN 1982-7636. pp. 664-683 http://www.e-publicacoes.uerj.br/index.php/redp/index

De acordo com Enrico Tullio Liebman, "as formas são necessárias, mas o formalismo é uma deformação" ". O autor faz críticas ao excesso de formalismo na consecução dos atos processuais. Segundo seu entendimento, as regras sobre procedimento têm a função de permitir um regular movimento do processo e, consequentemente, fornecer aos jurisdicionados a certeza e precisão dos atos. Ao mesmo tempo, condena a visão puramente legalista das formas, que atribui validade aos atos processuais somente quando realizados em conformidade com a lei. Para o jurista italiano, o que garante a validade dos atos processuais é o cumprimento de sua finalidade essencial no processo, mesmo que sua realização tenha ocorrido contrariamente à norma que o rege. Confere-se, desse modo, relevância ao princípio da instrumentalidade das formas, que visa a relacionar a validade do ato ao seu escopo ${ }^{10}$ no processo.

Alinhando a esse entendimento, o CPC/1973, nos arts. $154,244^{11}$ e $250^{12}$, criou mecanismos para afastar o excesso de formalismo. A literalidade de tais regras aponta para a possibilidade de convalidação de atos processuais executados de maneira diversa a da lei, quando estes conseguirem atingir sua finalidade essencial ${ }^{13}$, ainda que provenientes de uma violação formal que o próprio sistema puna com pena de nulidade. Nesse caso, o princípio da instrumentalidade se manifesta no sentido de tornar a atividade jurisdicional mais compatível com as noções de economia processual, celeridade e tutela eficiente do direito. Além do mais, vale ressaltar que o princípio da instrumentalidade das formas também cumpre com os princípios da convalidação, da causalidade e do interesse processual, todos pretendendo salvaguardar o processo das consequências do ato nulo, relativizando assim o desatendimento à forma em sentido estrito ${ }^{14}$.

\footnotetext{
${ }^{9}$ LIEBMAN, Enrico Tullio. Manual de direito processual civil. Vol. 1.2 ed. Tradução e notas de Cândido Rangel Dinamarco. Rio de Janeiro, 1985, p. 258.

10 "Ele significa que as formas não tem valor intrínseco próprio, sendo estabelecidas apenas como meio para atingir plenamente o escopo de cada ato; a necessidade de observá-las deve, por isso, ser medida em cada caso com o metro da consecução desse escopo". (LIEBMAN, Enrico Tullio. Manual de direito processual civil. Vol. 1.2 ed. Tradução e notas de Cândido Rangel Dinamarco. Rio de Janeiro, 1985, p. 230).

${ }^{11}$ Art. 244. Quando a lei prescrever determinada forma, sem cominação de nulidade, o juiz considerará válido $o$ ato se, realizado de outro modo, Ihe alcançar a finalidade.

12 Art. 250. O erro de forma do processo acarreta unicamente a anulação dos atos que não possam ser aproveitados, devendo praticar-se os que forem necessários, a fim de se observarem, quanto possível, as prescrições legais. Parágrafo único. Dar-se-á o aproveitamento dos atos praticados, desde que não resulte prejuízo à defesa.

13 GAJARDONI, Fernando da Fonseca. Flexibilidade procedimental: um novo enfoque para o estudo do procedimento em matéria processual. Tese de doutorado em Direito. USP/São Paulo, 2006, p. 120.

14 OLIVEIRA, Carlos Alberto Alvaro de. Do formalismo no processo civil. 4 ed. São Paulo: Saraiva, 2010, p. 265.
} 
Revista Eletrônica de Direito Processual - REDP. Volume 16. Julho a dezembro de 2015

Periódico Semestral da Pós-Graduação Stricto Sensu em Direito Processual da UERJ

Patrono: José Carlos Barbosa Moreira. ISSN 1982-7636. pp. 664-683 http://www.e-publicacoes.uerj.br/index.php/redp/index

Nota-se que, a partir da compreensão dos juristas Fernando da Fonseca Gajardoni e

Carlos Alberto Alvaro de Oliveira, acerca do princípio da instrumentalidade das formas, o "nosso próprio sistema parece ter dado à ordenação dos atos processuais bem menos valor do que na prática se tem emprestado a ela"15 e que o formalismo excessivo que tanto se discute no contexto brasileiro decorre, "em princípio, mais da cegueira do aplicador da lei [...] desatento aos valores do processo, pouco afeito ao manejo das possibilidades reparadoras contidas no ordenamento ou ansioso por facilitar seu trabalho - do que do próprio sistema normativo" $" 16$. Os autores consideram que apesar de haver, no ordenamento processual civil, normas que regem minuciosamente o procedimento, o legislador as relativizaram em benefício do princípio da instrumentalidade das formas. A partir disso, concluem que, no entanto, tal relativização tem sido negligenciada pelos operadores do direito que acabam insistindo em valorizar o formalismo procedimental.

A partir dessas considerações, cabe levantar o seguinte questionamento: há flexibilidade das regras de procedimento no processo civil brasileiro? Para responder a essa pergunta, convém apresentar o conceito de flexibilização procedimental e, em seguida, compará-lo à noção de instrumentalidade prevista nos arts. 154, 244 e 250 do Código de Processo Civil de 1973 objetivando, desse modo, verificar a existência ou não de uma correlação entre flexibilidade e instrumentalidade das formas.

A flexibilização procedimental está intrinsecamente relacionada à possibilidade de adequação dos atos processuais às realidades do caso concreto, ainda que em desacordo com as normas formais positivadas, o que permite a eliminação ou a modificação de atos devido à, respectivamente, sua desnecessidade e incompatibilidade quando comparados às realidades fáticas de uma demanda ${ }^{17}$.

Por sua vez, a instrumentalidade disposta nos arts. 154, 244 e 250 do CPC/73 parte de um foco diferente, não propriamente da adequação dos atos processuais às particularidades das demandas, mas da possibilidade de convalidação de atos realizados

\footnotetext{
15 GAJARDONI, Fernando da Fonseca. Flexibilidade procedimental: um novo enfoque para o estudo do procedimento em matéria processual. Tese de doutorado em Direito. USP/São Paulo, 2006, p. 121.

${ }^{16}$ OLIVEIRA, Carlos Alberto Alvaro de. Do formalismo no processo civil. 4 ed. São Paulo: Saraiva, 2010, p. 266.

17 “"... flexibilização traz embutida em si a aspiração de um sistema normativo que, pela impossibilidade de ser completo, permita alguma flexibilização. Ou seja, a flexibilização é sempre uma exceção, ainda que seja abertamente adotada em alguns países do civil law, como a França e Portugal." (COSTA, Henrique Araújo. Os poderes do juiz na Inglaterra e no Brasil: estudo comparado sobre os case management powers. Tese de doutorado em direito, PUC/SP, 2012, p. 22).
} 
Revista Eletrônica de Direito Processual - REDP. Volume 16. Julho a dezembro de 2015

Periódico Semestral da Pós-Graduação Stricto Sensu em Direito Processual da UERJ

Patrono: José Carlos Barbosa Moreira. ISSN 1982-7636. pp. 664-683 http://www.e-publicacoes.uerj.br/index.php/redp/index

contrariamente à lei, desde que atendidos seus escopos essenciais e não causem prejuízos à defesa das partes. Portanto, diferentemente dos fundamentos que sustentam a flexibilização procedimental, a instrumentalidade em comento busca, primordialmente, reconhecer a utilidade das formas no processo com a pretensão de validar atos praticados de modo diverso ao previsto em lei com o fulcro de salvar ou diminuir os efeitos do ato nulo, ou seja, há um interesse voltado mais especificamente para a economia e a celeridade processuais.

Vale ainda ressaltar que, de acordo com Cândido Rangel Dinamarco ${ }^{18}$, o princípio da instrumentalidade pode adotar duas feições diferentes. No tradicional processo legalista, como por exemplo o brasileiro, a instrumentalidade destina-se à atenuação e racionalização dos rigores das exigências formais, o que pode ser observado a partir do disposto nos artigos anteriormente comentados. Por outro lado, no processo marcado pela liberdade das formas, “em que não há uma ordem legal pré-estabelecida para a prática de atos processuais, competindo aos sujeitos do processo determinar a cada momento qual o ato processual a ser praticado"19, o princípio da instrumentalidade serve de parâmetro a essa liberdade amparando o respeito às garantias fundamentais como requisito de validade dos atos.

Feitas essas considerações, a instrumentalidade não se confunde com a flexibilização. O procedimento processual civil brasileiro adota o sistema da legalidade das formas ${ }^{20} \mathrm{em}$ que o modo, o local e o tempo que os atos processuais se realizarão encontram-se minuciosamente pré-estabelecidos em lei. Nesse contexto, uma hipotética violação a essas regras poderia incorrer em uma nulidade, ou não, a depender dos resultados gerados, se compatíveis ou não com a finalidade essencial do procedimento. A flexibilização pressupõe a adequação do procedimento às particularidades do caso concreto sem que isso seja considerado uma violação ao ordenamento jurídico vigente. Ou seja, enquanto a análise da instrumentalidade impõe a ocorrência de uma violação, a flexibilização advém de uma permissão legal. Constata-se, diante do exposto, a inflexibilidade (a rigidez ) do procedimento processual brasileiro.

\subsection{O procedimento}

\footnotetext{
${ }^{18}$ DINAMARCO, Cândido Rangel. A instrumentalidade do processo. 15 ed. São Paulo: Malheiros Ed., 2013, p. 155.

${ }^{19}$ GAJARDONI, Fernando da Fonseca. Procedimentos, déficit procedimental e flexibilização procedimental no novo CPC. Revista de informação legislativa, v. 48, n. 190 t.1, abr./jun. 2011, p. 164.

${ }^{20}$ GAJARDONI, Fernando da Fonseca. Procedimentos, déficit procedimental e flexibilização procedimental no novo CPC. Revista de informação legislativa, v. 48, n. 190 t.1, abr./jun. 2011, p. 164.
} 
Revista Eletrônica de Direito Processual - REDP. Volume 16. Julho a dezembro de 2015

Periódico Semestral da Pós-Graduação Stricto Sensu em Direito Processual da UERJ

Patrono: José Carlos Barbosa Moreira. ISSN 1982-7636. pp. 664-683 http://www.e-publicacoes.uerj.br/index.php/redp/index

O CPC de 1973 descreve o modo como os atos devem se desenvolver ao longo de um processo. O conjunto desses atos, que se sucedem ordenadamente em direção ao objetivo que pretende alcançar determinado processo, chama-se procedimento. No sistema processual brasileiro, este é marcado por um rigor formal concebido, por parte da doutrina, como essencial à previsibilidade e à segurança jurídica.

Conforme a natureza da prestação jurisdicional pretendida, o procedimento a ser utilizado pode variar uma vez que não se encontra completamente dissociado do direito material $^{21}$. Com isso, torna-se necessária a existência de procedimentos diferenciados. Ainda, o CPC/73 classifica os processos, levando em consideração a natureza da tutela demandada, em: processo de conhecimento (livro I), processo de execução (livro II) e processo cautelar (livro III), os quais são disciplinados em três livros diferentes, cada qual descrevendo os seus respectivos procedimentos.

No processo de conhecimento, também conhecido como de cognição, a função jurisdicional atém-se basicamente ao reconhecimento de um direito material frente a uma situação concreta. Ademais, com a criação da Lei 11.232/2005, que estabeleceu a fase de cumprimento de sentença dentro do processo de conhecimento, houve uma ampliação de sua função, que foi acrescida da atuação prática da norma jurídica concreta ${ }^{22}$. Tendo em vista essas diferentes finalidades e as especificidades do direito material a ser tutelado, os procedimentos dividem-se em: comum (que subdivide-se em ordinário e sumário) e especial (que podem ser de jurisdição contenciosa ou de jurisdição voluntária).

Por sua vez, o processo de execução, com base em títulos executivos judiciais ou extrajudiciais, visa ao cumprimento de uma sentença proferida em anterior processo de conhecimento ou dar eficácia a títulos legalmente considerados como extrajudiciais (tais títulos podem, por si só, ensejar a tutela executiva, a exemplo do que ocorrem com os títulos de crédito). Tem-se como requisito para uma execução legítima a existência de uma

\footnotetext{
21 "A ideia de procedimento puro ou de procedimento neutro abriu espaço à tentativa de instituição de um procedimento comum ou de um procedimento ordinário para trata de todo e qualquer caso conflitivo. [...] Acontece que apenas um procedimento [...] jamais poderá dar conta das várias necessidade de tutela do direito material". (MARINONI, Luiz Guilherme. Teoria geral do processo. Volume 1. 8 ed. São Paulo: Revista dos tribunais, 2014, p. 430-433). Sobre a importância da conexão entre o direito processual e o direito material, Liebman tratou o assunto da seguinte forma: "O estudo do direito processual, especialmente o do processual civil, deve, por isso, ser levado a cabo sempre com viva atenção às suas ligações com o direito material, sem o que se corre o risco de reduzi-lo a um pouco interessante computar de formalidade e prazos" (LIEBMAN, Enrico Tullio. Manual de direito processual civil. Volume 1. 2 ed. Tradução e notas de Cândido Rangel Dinamarco. Rio de Janeiro, 1985, p.35).

${ }^{22}$ MOREIRA, José Carlos Barbosa. O novo processo civil brasileiro: exposição sistemática do procedimento. 29 ed. Rio de Janeiro: Forense, 2012, p. 3.
} 
Revista Eletrônica de Direito Processual - REDP. Volume 16. Julho a dezembro de 2015

Periódico Semestral da Pós-Graduação Stricto Sensu em Direito Processual da UERJ

Patrono: José Carlos Barbosa Moreira. ISSN 1982-7636. pp. 664-683 http://www.e-publicacoes.uerj.br/index.php/redp/index

obrigação certa, líquida e exigível. Diferentemente do que ocorre no processo de conhecimento, no processo executivo o procedimento está mais fortemente restrito ao tipo do título apresentado, portanto, "a cada espécie de prestação corresponde um tipo de procedimento, inexistindo qualquer paradigma geral a que os vários tipos comportem referência" ${ }^{, 23}$.

Por fim, o processo cautelar visa à tomada de providências de caráter urgente em que haja necessidade de preservação ou reintegração de um direito subjetivo ameaçado ou lesado ou da ordem jurídica em si. As medidas acautelatórias podem seguir dois ritos diferentes: o rito comum ou o rito especial. As regras do procedimento comum estão dispostas na primeira parte do Livro III as quais abrangem o processamento de grande parte das cautelares. $\mathrm{Na}$ segunda parte, o Código descreve os procedimentos especiais cautelares os quais adotam trâmites específicos para determinadas matérias ${ }^{24}$.

Nota-se que a atividade processual brasileira é em essência organizada mediante critérios artificiais, criados pelo legislador. Na tentativa de classificar as demandas encaminhadas ao Judiciário em grupos e, com isso, facilitar a escolha do procedimento a ser utilizado no processamento de determinado feito, apreciou-se a natureza do direito material como critério para a referida classificação. Vale lembrar, no entanto, que "ainda que o legislador edite um procedimento adequado a uma situação de direito substancial, isto jamais bastará para atender as circunstâncias do caso concreto. Não há como confundir uma necessidade de direito material - pensada em abstrato - e as peculiaridades do caso concreto" ${ }^{25}$. Portanto, mesmo diante da previsão de inúmeros procedimentos em nosso ordenamento processual civil, estes são insuficientes para atender, verdadeiramente, as necessidades específicas de uma situação concreta.

\section{A FLEXIBILIZAÇÃO PROCEDIMENTAL NA TRAMITAÇÃO LEGISLATIVA DO NOVO CÓDIGO DE PROCESSO CIVIL}

Ao longo do processo legislativo do Novo Código de Processo Civil, foram cogitadas mudanças significativas com relação às normas relativas ao procedimento, mais

\footnotetext{
${ }^{23}$ MOREIRA, José Carlos Barbosa. O novo processo civil brasileiro: exposição sistemática do procedimento. 29 ed. Rio de Janeiro: Forense, 2012, p. 209.

${ }^{24}$ MOREIRA, José Carlos Barbosa. O novo processo civil brasileiro: exposição sistemática do procedimento. 29 ed. Rio de Janeiro: Forense, 2012, p. 306-321.

${ }^{25}$ MARINONI, Luiz Guilherme. Teoria geral do processo. Volume 1.8 ed. São Paulo: Revista dos tribunais, 2014, p. 434.
} 
Revista Eletrônica de Direito Processual - REDP. Volume 16. Julho a dezembro de 2015

Periódico Semestral da Pós-Graduação Stricto Sensu em Direito Processual da UERJ

Patrono: José Carlos Barbosa Moreira. ISSN 1982-7636. pp. 664-683 http://www.e-publicacoes.uerj.br/index.php/redp/index

especificamente, quanto à possibilidade de flexibilização diante de hipóteses concretas que demandem um tratamento diferenciado do caso. Para compreender a complexidade de tal tema, faz-se necessário entender as fases e os percursos seguidos pelo referido código até o presente momento e as principais emendas propostas pelas casas do Congresso Nacional responsáveis por provocar alterações significativas de sentido dos dispositivos que tratam sobre o assunto.

Em setembro de 2009, foi instituída uma comissão de juristas para elaboração do Anteprojeto do Novo Código de Processo Civil por ato ${ }^{26}$ do presidente do Senado Federal, José Sarney. Em junho de 2010, esta comissão finalizou seus trabalhos com a apresentação do texto que, então, viria a ser analisado por uma comissão formada de Senadores nomeados especificamente para este fim.

Iniciou-se a tramitação do projeto de lei no Senado Federal (PLS 166/2010). A comissão de Senadores foi instalada em agosto de 2010 e presidida pelo Senador Demóstenes Torres que designou Valter Pereira como Relator-geral. As atividades da comissão tiveram como objetivo "ouvir todos os seguimentos interessados de modo a, ao final, suprir eventuais omissões, corrigir ocasionais deficiências e excluir equívocos para entregar à sociedade um Código que se constitua um moderno instrumento de aplicação do Direito"27. Para esse fim, foram realizadas audiências públicas e reuniões com especialistas da área e analisadas as sugestões encaminhadas por órgãos e instituições atingidas pelo projeto. Em dezembro de 2010, foi apresentada a redação vencida do Substitutivo ao Projeto de Lei $n^{\text {o }} 166 / 2010^{28}$.

Aprovado o projeto no Senado Federal (casa iniciadora), este passou a tramitar na Câmara dos Deputados, para revisão, como Projeto de Lei 8.046/2010. Nessa ocasião, foi designado como Relator-geral da Comissão especial destinada a proferir parecer ao projeto o Deputado Sérgio Barradas Carneiro. Após a apresentação de emendas pela comissão, foi aprovada, em março de 2014, a redação do Substitutivo da Câmara dos Deputados.

Em abril de 2014, o projeto retornou ao Senado Federal sob a relatoria do Senador Vital de Rêgo. A Comissão Temporária destinada à análise do Substituto da Câmara ao

\footnotetext{
${ }^{26}$ Ato do presidente $\mathrm{n}^{\circ} 379$ de 2009 que instituiu a comissão de juristas responsável pela elaboração do anteprojeto do novo Código de Processo Civil.

${ }^{27}$ Plano de Trabalho da comissão temporária destinada à análise do projeto de novo código de processo civil. Disponível em: $<$ http://www.senado.gov.br/atividade/materia/getPDF.asp?t=81947\&tp=1 $>$. Acesso em: 8 de out. 2014.

${ }_{28}$ Redação do Substitutivo do PLS 166/2010. Disponível em: < http://www.senado.gov.br/atividade/materia/getPDF.asp?t=85510\&tp=1>. Acesso em: 8 de out. 2014.
} 
Revista Eletrônica de Direito Processual - REDP. Volume 16. Julho a dezembro de 2015

Periódico Semestral da Pós-Graduação Stricto Sensu em Direito Processual da UERJ

Patrono: José Carlos Barbosa Moreira. ISSN 1982-7636. pp. 664-683 http://www.e-publicacoes.uerj.br/index.php/redp/index

Projeto de lei do Senado Federal no 166, de 2010 (NCPC), apresentou seu parecer sobre a redação final do projeto do NCPC o qual foi submetido à votação na referida Casa em 17 de dezembro de 2014. Aprovada a redação final, o projeto foi encaminhado à sanção presidencial, momento em que sofreu veto parcial. A publicação do Código ocorreu em 17 de março de 2015 e que, conforme o seu art. 1.045, passa a vigorar após decorrido um ano de sua publicação oficial.

\subsection{As novidades apresentadas no Anteprojeto do Novo Código de Processo Civil}

As propostas de mudanças introduzidas no Anteprojeto do Novo Código de Processo Civil, formulada pela comissão de juristas ${ }^{29}$, fundaram-se, de modo geral, na busca pela eficiência da tutela jurisdicional. Eficiência esta que tem se evidenciado inconsistente quando analisada do ponto de vista do sistema processual civil vigente, seja por conta do enfraquecimento da coesão entre as suas normas provocado pelas significativas alterações efetuadas no código a partir dos anos de 1994 e 1995, seja devido a sua omissão diante das necessidades sociais. Constatado tais fatos, o trabalho da comissão voltou-se para a identificação e manutenção de dispositivos do CPC/1973 cujos efeitos ainda geram resultados positivos, a diminuição da complexidade em prol de um processo mais célere e justo e a instrumentalização do processo com o escopo de assegurar o cumprimento do direito material. Desse modo, as atividades realizadas pela comissão tomaram como diretrizes os seguintes objetivos:

1) estabelecer expressa e implicitamente verdadeira sintonia fina com a Constituição Federal;

2) criar condições para que o juiz possa proferir decisão de forma mais rente à realidade fática subjacente à causa;

3) simplificar, resolvendo problemas e reduzindo a complexidade de subsistemas, como, por exemplo, o recursal;

4) dar todo o rendimento possível a cada processo em si mesmo considerado; e,

\footnotetext{
${ }^{29}$ Os membros designados para compor a comissão de juristas destinada à elaboração do Anteprojeto do Novo Código de Processo Civil foram: Luiz Fux (Presidente), Teresa Arruda Alvim Wambier (Relatora), Adroaldo Furtado Fabrício, Humberto Theodoro Júnior, Paulo Cesar Pinheiro Carneiro, José Roberto dos Santos Bedaque Almeida, José Miguel Garcia Medina, Bruno Dantas, Jansen Fialho de Almeida, Benedito Cerezzo Pereira Filho, Marcus Vinicius Furtado Coelho e Elpídio Donizetti Nunes. Disponível em: $<$ http://www.senado.gov.br/senado/novocpc/pdf/Anteprojeto.pdf $>$. Acesso em: 8 de out. 2014.
} 
Revista Eletrônica de Direito Processual - REDP. Volume 16. Julho a dezembro de 2015

Periódico Semestral da Pós-Graduação Stricto Sensu em Direito Processual da UERJ

Patrono: José Carlos Barbosa Moreira. ISSN 1982-7636. pp. 664-683 http://www.e-publicacoes.uerj.br/index.php/redp/index

5) finalmente, sendo talvez este último objetivo parcialmente alcançado pela realização daqueles mencionados antes, imprimir maior grau de organicidade ao sistema, dando-lhe, assim, mais coesão. ${ }^{30}$

Foram esses objetivos que motivaram as modificações sugeridas pela comissão. Quanto à questão da flexibilização do procedimento, ganha relevo os objetivos de n. 2 e 4 os quais alinham-se à noção de processo como instrumento inserido no contexto social ${ }^{31}$, portanto, passível de modificações que visam à sua adaptação às particularidades do caso concreto permitindo, desse modo, que cada processo tenha maior rendimento possível ${ }^{32}$. Com base nesses pontos, foram criados os artigos 107, inciso V e 151, $\S 1^{\circ}$, os quais tinham como intenção dar efetividade às necessidades aduzidas dos objetivos mencionados pela comissão:

Art. 107. O juiz dirigirá o processo conforme as disposições deste Código, incumbindo-lhe: $\mathrm{V}$ - adequar as fases e os atos processuais às especificações do conflito, de modo a conferir maior efetividade à tutela do bem jurídico, respeitando sempre o contraditório e a ampla defesa.

Art.151. Os atos e os termos processuais não dependem de forma determinada, senão quando a lei expressamente a exigir, considerando-se válidos os que, realizados de outro modo, the preencham a finalidade essencial. §1o Quando o procedimento ou os atos a serem realizados se revelarem inadequados às peculiaridades da causa, deverá o juiz, ouvidas as partes e observados o contraditório e a ampla defesa, promover o necessário ajuste.

Vale ressaltar que a origem da ideia de se conferir ao magistrado o poderdever de adaptar o procedimento às situações dos casos concretos, exposta no Anteprojeto, partiu da análise de experiências jurídicas externas, tal como o case management powers do processo civil inglês (Civil Procedure Rules, 1999) em que o juiz exerce um papel ativo na condução do processo, o que permite, por exemplo, a suspensão ou a supressão de atos e prazos processuais. De acordo com a sistematização apresentada por Fernando da Fonseca Gajardoni, a condução ativa do processo pelo juiz que permite a adaptação do procedimento

\footnotetext{
30 Anteprojeto do Novo Código de Processo Civil. Disponível em: $<$ http://www.senado.gov.br/senado/novocpc/pdf/Anteprojeto.pdf $>$. Acesso em: 8 de out. 2014.

31 Anteprojeto do Novo Código de Processo Civil. Disponível em: $<$ http://www.senado.gov.br/senado/novocpc/pdf/Anteprojeto.pdf $>$. Acesso em: 8 de out. 2014, p. 22.

32 Anteprojeto do Novo Código de Processo Civil. Disponível em: $<$ http://www.senado.gov.br/senado/novocpc/pdf/Anteprojeto.pdf $>$. Acesso em: 8 de out. 2014, p. 29.
} 
Revista Eletrônica de Direito Processual - REDP. Volume 16. Julho a dezembro de 2015

Periódico Semestral da Pós-Graduação Stricto Sensu em Direito Processual da UERJ

Patrono: José Carlos Barbosa Moreira. ISSN 1982-7636. pp. 664-683

http://www.e-publicacoes.uerj.br/index.php/redp/index

às variantes do caso concreto, buscando atingir uma adequada tutela, pode ser compreendido como "flexibilização procedimental legal genérica" 33 .

\subsection{A tramitação do projeto no Senado Federal}

Iniciada a tramitação do projeto de lei n. 166/2010 no Senado Federal, a flexibilização procedimental disciplinada nos arts. 107, V e 151, §1 $1^{\circ}$, do Anteprojeto do Novo CPC, foi um entre dois pontos do projeto "mais criticado em audiências públicas, bem como nas propostas apresentadas pelos Senadores e pelas diversas manifestações" ${ }^{34}$ encaminhadas à Casa legislativa.

Os Senadores Francisco Dornelles ${ }^{35}$ e Adelmir Santana ${ }^{36}$ propuseram as emendas de $\mathrm{n}^{\mathrm{o}} 15,16$ e 21 objetivando a supressão de tais artigos do projeto. Os principais argumentos que justificaram essa proposição foram os de que o procedimento integra a noção de devido processo legal; de que a mudança do procedimento pelo juiz constituiria uma arbitrariedade; de que as regras processuais são normas de direito público que servem para conter o poder do juiz e orientar a estratégia de defesa da parte; e de que houve um desvirtuamento das regras inglesas que serviram de inspiração para a elaboração desses dispositivos uma vez que naquelas o legislador britânico se atentou em apresentar um rol específico e detalhado dos poderes conferidos ao juiz, enquanto que nesses não houve a delimitação da atuação do magistrado ficando ao seu arbítrio o poder de alterar regras.

Em audiência pública realizada em 2 de dezembro de 2010, o jurista Antônio Claudio da Costa Machado ${ }^{37}$ expôs críticas contra tais dispositivos que, no seu entendimento,

\footnotetext{
33 GAJARDONI, Fernando da Fonseca. Flexibilidade procedimental: um novo enfoque para o estudo do procedimento em matéria processual. Tese de doutorado em Direito. USP/São Paulo, 2006, p. 158.

34 Relatório Final apresentado pelo Senador Valter Pereira em 24 de nov. 2010, p. 144. Disponível em: < http://www.senado.gov.br/atividade/materia/getPDF.asp?t=83984\&tp=1>. Acesso em: 9 de out. 2014.

35 Emendas propostas pelo Senador Francisco Dornelles estão disponíveis em: $<$ http://www.senado.gov.br/atividade/materia/getPDF.asp?t=82256\&tp=1>. Acesso em: 9 de out. 2014.

36 Emendas propostas pelo Senador Adelmir Santana estão disponíveis em: < http://www.senado.gov.br/atividade/materia/getPDF.asp?t=82279\&tp=1 >. Acesso em: 9 de out. 2014.

${ }^{37}$ Doutor em direito pela Universidade de São Paulo (1997), mestre em direito pela Universidade de São Paulo (1989), graduado em direito pela Universidade de São Paulo (1982). professor do mestrado em direito do Centro UNIFIEO (2000), ministra as disciplinas: instrumentos processuais infra-constitucionais, princípios constitucionais do processo, ainda no UNIFIEO ministra aula no curso de especialização em direito civil e processo civil (2004) com as disciplinas: teoria geral do processo, teoria geral dos recursos e tutela de urgência e de garantia. professor da graduação da FADUSP (1983), ministra as disciplinas: teoria geral do processo, direito processual civil, procedimentos especiais, processo civil aplicado e procedimentos civis do ECA. Atua principalmente nos seguinte tema: direito processual civil. Disponível em: $<$ https://uspdigital.usp.br/tycho/CurriculoLattesMostrar?codpub=07A36A3F3CB0>. Acesso em: 12 de out. 2014.
} 
Revista Eletrônica de Direito Processual - REDP. Volume 16. Julho a dezembro de 2015

Periódico Semestral da Pós-Graduação Stricto Sensu em Direito Processual da UERJ

Patrono: José Carlos Barbosa Moreira. ISSN 1982-7636. pp. 664-683 http://www.e-publicacoes.uerj.br/index.php/redp/index

outorgavam excessivos poderes aos juízes de primeira instância; advertiu sobre os riscos que

o processo civil estava correndo de se tornar um instrumento autoritário; e, apontou a tendência do processo civil em se transformar em um processo do trabalho em que cada juiz "acaba aplicando o código de processo que tem na sua cabeça"38.

Diante das discussões suscitadas pela inclusão da matéria da flexibilização procedimental nos referidos dispositivos pelo Anteprojeto do Novo Código de Processo Civil, as emendas de $\mathrm{n}^{\mathrm{o}} 15$ e 16 foram parcialmente acolhidas no sentido de limitar a flexibilização do procedimento pelo juiz a duas hipóteses: aumento de prazos e inversão do ônus de prova ${ }^{39}$. Quanto à emenda de $\mathrm{n}^{0} 21$, essa foi totalmente acolhida no sentido de suprimir a redação do art. $151, \S 1^{\circ}$, do Anteprojeto por tratar de matéria idêntica ao art. 107, $\mathrm{V}^{40}$. O argumento central que resultou na mitigação da flexibilização voltou-se, basicamente, para a tese de que a ampla adequação do procedimento pelo juiz, frente às peculiaridades do caso concreto, geraria insegurança jurídica.

O substitutivo apresentado pelo Senado Federal passou então a disciplinar a matéria do seguinte modo:

Art. 118. O juiz dirigirá o processo conforme as disposições deste Código, incumbindo-lhe: $\mathrm{V}$ - dilatar os prazos processuais e alterar a ordem de produção dos meios de prova adequando-os às necessidades do conflito, de modo a conferir maior efetividade à tutela do bem jurídico.

Nessa etapa do processo legislativo, a flexibilização procedimental restringiu-se à dilatação de prazos processuais e à alteração da ordem de produção do meios de prova.

\footnotetext{
${ }^{38}$ Ata da $7^{\mathrm{a}}$ Reunião da Comissão, audiência pública, na cidade de São Paulo - SP. Publicação em 02/12/2010 no DSF, p. 55115-55116. Disponível em: $<$ http://legis.senado.leg.br/diarios/BuscaDiario?tipDiario=1\&datDiario=02/12/2010\&paginaDireta=55098>. Acesso em: 10 de out. de 2014.

39 “A Emenda n 15 merece acolhimento parcial. Como já registrado, a previsão do art. 107, V, foi um dos pontos mais criticados do projeto, já que, tal como posto, permite ao Juiz alterar, de acordo com seu entendimento, qualquer fase do processo. Segundo a maioria, na prática, isso pode permitir que cada juiz faça o seu "Código", o que pode gerar insegurança jurídica. Por isso, a regra realmente deve ser alterada. Assim, no substitutivo, a flexibilização procedimental fica limitada a duas hipóteses: aumento de prazos e a inversão da produção dos meios de prova". "A Emenda n 16 é idêntica à emenda 15. Assim, pelos mesmos fundamentos, também a acolhemos parcialmente". Parecer da Comissão temporária da Reforma do Código de Processo Civil, p. 199. Disponível em: $<$ http://www.senado.gov.br/atividade/materia/getPDF.asp?t=83984\&tp=1>. Acesso em: 10 de out. de 2014.

40 “"A Emenda n 21 merece acolhimento integral. . O art. 151, § 1 o do PLS n ${ }^{\circ} 166$, de 2010, repete, em parecidos termos, o que está previsto no art. 107, V, que, ao seu turno, como dito, foi substancialmente alterado. Realmente, o parágrafo deve ser excluído porque a possibilidade de o juiz alterar qualquer fase do processo pode gerar insegurança jurídica. Parecer da Comissão temporária da Reforma do Código de Processo Civil, p. 200. Disponível em: $<$ http://www.senado.gov.br/atividade/materia/getPDF.asp?t=83984\&tp=1>. Acesso em: 10 de out. de 2014.
} 
Revista Eletrônica de Direito Processual - REDP. Volume 16. Julho a dezembro de 2015

Periódico Semestral da Pós-Graduação Stricto Sensu em Direito Processual da UERJ

Patrono: José Carlos Barbosa Moreira. ISSN 1982-7636. pp. 664-683 http://www.e-publicacoes.uerj.br/index.php/redp/index

\subsection{O substitutivo apresentado pela Câmara dos Deputados}

Na Câmara dos Deputados, o projeto de lei passou a tramitar como PL 8.046/2010. Nessa ocasião, foram propostas 900 emendas ao projeto aprovado no Senado Federal, sendo que as de $n^{\circ} 222,788,805$ e 859 tangiam a flexibilização procedimental.

As emendas de $n^{\circ} 788$ e 805 de autoria do Deputado Miro Teixeira propuseram a eliminação de todo e qualquer tipo de flexibilização procedimental do ordenamento processual diante das respectivas propostas de alteração da redação do art. 118, que apresenta o rol de deveres dos magistrados, e de supressão do inciso $\mathrm{V}$ do art. 118 do substitutivo Senado Federal. A ideia da emenda $n^{0} 788$ foi inicialmente apresentada pelo professor Antônio Cláudio da Costa Machado sob o fundamento de que "vivemos em um Estado Democrático de Direito e sob a égide do princípio do devido processo legal, agride a Constituição Federal a ideia de conferir superpoderes aos juízes de primeiro grau, dentre os quais, o de mexer no procedimento" e, por isso, a possibilidade de o juiz dilatar prazos e alterar a ordem de produção dos meios de provas adequando-os às necessidades do conflito, transformaria a garantia do "devido processo legal" em "devido processo judicial".

A proposta de emenda $n^{\circ} 805$ foi encaminhada pelo jurista Caio Leonardo Bessa Rodrigues, presidente da comissão de acompanhamento da reforma do Código de Processo Civil da Ordem dos Advogados/DF. A supressão do inciso V do art. 118 partiu da noção de que a "ação estatal deve ser contida nos limites claros da Lei", sob risco de por em xeque a segurança jurídica. De acordo com o autor da proposta, o rigor do formalismo poderia ser limitado diante das particularidades do caso concreto, desde que as hipóteses de adaptação das regras estivessem previamente previstas em $1 \mathrm{i}^{41}$. Essa dependência legal para a

\footnotetext{
${ }^{41} \mathrm{O}$ autor da proposta de emenda apresentou exemplos em que o legislador permite ao magistrado, de acordo com os casos especificados em lei, adaptar o procedimento frente determinadas particularidades de um caso concreto. Para isso citou trecho do texto de Fredie Didier Jr: "Podem ser citadas, apenas como exemplos: a) possibilidade de inversão da regra do ônus da prova, em causas de consumo (a regra do procedimento é alterada no caso concreto, ope iudicis, preenchidos certos requisitos), de acordo com o art. 6o, VIII, CDC; b) a possibilidade de conversão do procedimento sumário em ordinário, em razão da complexidade da prova técnica ou do valor da causa (art. 277, §§ 4o e 5o, CPC); c) o julgamento antecipado da lide, em que se pode abreviar o rito, com a supressão de uma de suas fases (art. 330, CPC); d) a determinação ou não de audiência preliminar, a depender da disponibilidade do direito em jogo (art. 331, CPC); e) as variantes procedimentais previstas na Lei de Ação Popular (LF 4.717/65, art. 7o e segs.); f) a possibilidade de o relator da ação rescisória fixar o prazo de resposta, dentro de certos parâmetros (art. 491, CPC); g) as mutações permitidas ao agravo de instrumento do art. 544, CPC, previstas em seus parágrafos etc." (DIDIER JR., Fredie. Sobre dois importantes, e esquecidos, princípios do processo: adequação e adaptabilidade do procedimento. Disponível em: $<$ http://www.mundojuridico.adv.br/cgi-bin/upload/texto073.doc>. Acesso em 12 de out. 2014).
} 
Revista Eletrônica de Direito Processual - REDP. Volume 16. Julho a dezembro de 2015

Periódico Semestral da Pós-Graduação Stricto Sensu em Direito Processual da UERJ

Patrono: José Carlos Barbosa Moreira. ISSN 1982-7636. pp. 664-683 http://www.e-publicacoes.uerj.br/index.php/redp/index

promoção de adaptação pelo juiz alinha-se ao chamado "sistema de flexibilização por força da lei" ${ }^{\prime 2}$.

Por sua vez, a emenda $n^{\circ} 859$ do Deputado Jerônimo Goergen retoma a noção inicial de flexibilização apresentada no anteprojeto ao apresentar uma nova redação ao art. 118 e estabelecendo no inciso VII o dever de o juiz "adequar as fases e os atos processuais às especificidades da tutela do direito postulada em juízo, de modo a conferir maior efetividade à tutela jurisdicional, observado o contraditório". Destacou, o Deputado, a necessidade de cooperação na direção do processo e o dever do magistrado de assegurar a igualdade de tratamento entre as partes.

As emendas $n^{\circ} 222,788$ e 805 restaram rejeitadas e a emenda $\mathrm{n}^{\circ} 859$ foi parcialmente acolhida. Nota-se que as discussões sobre o projeto ocorridas no âmbito da Câmara dos Deputados retomaram, em parte, a noção inicial da importância da flexibilização procedimental apresentada pelo Anteprojeto do CPC. Por meio da leitura das justificativas de rejeição de tais emendas ${ }^{43}$, observou-se a valorização do princípio da adequação formal, que estaria em consonância com as demandas apresentadas por boa parte da doutrina nacional e alinhada às mudanças que vêm ocorrendo no direito estrangeiro como, por exemplo, no direito português. Desse modo, manteve-se no substitutivo apresentado pela Câmara do Deputados a possibilidade de o juiz dilatar prazos processuais e alterar a ordem de produção dos meios de prova com a finalidade de adequá-los às necessidade do conflito:

Art. 139. O juiz dirigirá o processo conforme as disposições deste Código, incumbindo-lhe: VI - dilatar os prazos processuais e alterar a ordem de produção dos meios de prova, adequando-os às necessidades do conflito de modo a conferir maior efetividade à tutela do direito.

Ademais, algumas inovações, no tocante ao tema da flexibilização procedimental, foram realizadas no sentido de ampliar os poderes das partes na regulação do procedimento e dos prazos processuais. Por intermédio de acordo firmado entre partes plenamente capazes e em situação de equilíbrio de poder sobre direitos que admitam a sua autocomposição, o art. 191 do substitutivo da $\mathrm{CD}$ procura tornar viável o ajuste do procedimento às

\footnotetext{
${ }^{42}$ GAJARDONI, Fernando da Fonseca. Flexibilidade procedimental: um novo enfoque para o estudo do procedimento em matéria processual. Tese de doutorado em Direito. USP/São Paulo, 2006, p. 157.

${ }^{43}$ Relatório-geral da Comissão especial destinada a proferir parecer ao projeto de lei $\mathrm{n}^{\circ} 6.025$, de 2005 , ao projeto de lei $\mathrm{n}^{\circ}$ 8.046, de 2010, ambos do Senado Federal, e outros, que tratam do "código de processo civil", p. 486-487. Disponível em: http://www.camara.gov.br/proposicoesWeb/fichadetramitacao?idProposicao=490267>. Acesso em: 13 de out. 2014.
} 
Revista Eletrônica de Direito Processual - REDP. Volume 16. Julho a dezembro de 2015

Periódico Semestral da Pós-Graduação Stricto Sensu em Direito Processual da UERJ

Patrono: José Carlos Barbosa Moreira. ISSN 1982-7636. pp. 664-683 http://www.e-publicacoes.uerj.br/index.php/redp/index

especificidades da causa, a convenção acerca dos ônus, poderes, faculdades e deveres processuais de cada uma das partes:

Art. 191. Versando a causa sobre direitos que admitam autocomposição, é lícito às partes plenamente capazes convencionar sobre os seus ônus, poderes, faculdades e deveres processuais, antes ou durante o processo.

$\S 10$ De comum acordo, o juiz e as partes podem estipular mudanças no procedimento para ajustá-lo às especificidades da causa, fixando calendário para a prática dos atos processuais, quando for o caso.

$\S 20$ O calendário vincula as partes e o juiz, e os prazos nele previstos somente serão modificados em casos excepcionais, devidamente justificados.

§ 3o Dispensa-se a intimação das partes para a prática de ato processual ou a realização de audiência cujas datas tiverem sido designadas no calendário.

$\S 40$ De ofício ou a requerimento, o juiz controlará a validade das convenções previstas neste artigo, recusando-lhes aplicação somente nos casos de nulidade ou inserção abusiva em contrato de adesão ou no qual qualquer parte se encontre em manifesta situação de vulnerabilidade.

Observa-se, portanto, uma tentativa de ampliar a participação das partes na condução do processo que, por meio de acordo, teriam a possiblidade de alterar regras de procedimento e fixar prazos para a prática de atos processuais.

\section{A FLEXIBILIZAÇÃo NO NOVO CÓDIGO DE PROCESSO CIVIL}

Após a aprovação da redação final na Câmara dos Deputados, o projeto retornou ao Senado Federal, em abril de 2014, para a apreciação exclusiva das emendas feitas no âmbito casa revisora (Câmara dos Deputados) as quais passariam a ser passíveis de rejeição ou acolhimento por parte da casa iniciadora ${ }^{44}$. Até junho de 2014 foi oferecido o total de 186 emendas de redação ou supressiva ${ }^{45}$, nenhuma delas, entretanto, insurgiu-se contra o conteúdo do art. 191 e seus incisos, do Substitutivo da Câmara dos Deputados ${ }^{46}$. Desse

\footnotetext{
${ }^{44}$ Art. 65, CF/88. O projeto de lei aprovado por uma Casa será revisto pela outra, em um só turno de discussão e votação, e enviado à sanção ou promulgação, se a Casa revisora o aprovar, ou arquivado, se o rejeitar. Parágrafo único. Sendo o projeto emendado, voltará à Casa iniciadora.

${ }^{45}$ Relatório de emendas apresentadas no prazo estabelecido no Plano de trabalho do Relator Senador Vital do Rêgo. Disponível em: <http://www.senado.gov.br/atividade/materia/getPDF.asp?t=152359\&tp=1>. Acesso em: 8 de out. 2014.

46 Houve um mero ajuste redacional do $\S 4^{\circ}$ do dispositivo 191 que substituiu a palavra "qualquer" por "alguma", "de maneira a torná-lo mais ajustado ao vernáculo". Alteração proposta pelo Relator Vital do Rêgo.
} 
Revista Eletrônica de Direito Processual - REDP. Volume 16. Julho a dezembro de 2015

Periódico Semestral da Pós-Graduação Stricto Sensu em Direito Processual da UERJ

Patrono: José Carlos Barbosa Moreira. ISSN 1982-7636. pp. 664-683 http://www.e-publicacoes.uerj.br/index.php/redp/index

modo, a flexibilização manteve-se nos mesmos moldes da redação apresentada pela casa revisora.

A Comissão Temporária destinada à análise do Substituto da Câmara ao Projeto de lei do Senado Federal $n^{\circ}$ 166, de 2010 (NCPC) realizou pequenos ajustes no sentido de dividir em dois artigos diferentes (arts. 190 e 191) o conteúdo que antes encontrava-se em um único dispositivo:

Art. 190. Versando o processo sobre direitos que admitam autocomposição, é lícito às partes plenamente capazes estipular mudanças no procedimento para ajustá-lo às especificidades da causa e convencionar sobre os seus ônus, poderes, faculdades e deveres processuais, antes ou durante o processo.

Parágrafo único. De ofício ou a requerimento, o juiz controlará a validade das convenções previstas neste artigo, recusando-lhes aplicação somente nos casos de nulidade ou de inserção abusiva em contrato de adesão ou em que alguma parte se encontre em manifesta situação de vulnerabilidade.

Art. 191. De comum acordo, o juiz e as partes podem fixar calendário para a prática dos atos processuais, quando for o caso.

$\S 1$ o O calendário vincula as partes e o juiz, e os prazos nele previstos somente serão modificados em casos excepcionais, devidamente justificados.

§ 2o Dispensa-se a intimação das partes para a prática de ato processual ou a realização de audiência cujas datas tiverem sido designadas no calendário.

Após a aprovação da redação final do projeto do novo código ${ }^{47}$, em 17 de dezembro de 2014, este foi submetido à sanção do Presidente da República. Não houve veto presidencial no que tange à matéria da flexibilização procedimental.

Portanto, a forma de adequação do procedimento preconizada no NCPC, que inclui a participação das partes, aproxima-se da noção de "flexibilização voluntária das regras de procedimento" sistematizada por Fernando Gajardoni ${ }^{48}$.

\section{CONCLUSÃO}

Parecer $\quad \mathrm{n}^{\mathrm{o}}$ 956, de 2014, 0 p. $97 . \quad$ Disponível em: $<$ http://www.senado.gov.br/atividade/materia/getPDF.asp?t=159354\&tp=1 > Acesso em: 25 de abr. de 2015.

${ }^{47}$ Redação final do Substitutivo da Câmara dos Deputados ao Projeto de Lei do Senado no 166, de 2010 (no 8.046, de 2010, naquela Casa). Disponível em: <http://legis.senado.leg.br/mateweb/arquivos/matepdf/160741.pdf>. Acesso em: 25 de abr. de 2015.

${ }^{48}$ GAJARDONI, Fernando da Fonseca. Flexibilidade procedimental: um novo enfoque para o estudo do procedimento em matéria processual. Tese de doutorado em Direito. USP/São Paulo, 2006, p. 158. 
Revista Eletrônica de Direito Processual - REDP. Volume 16. Julho a dezembro de 2015

Periódico Semestral da Pós-Graduação Stricto Sensu em Direito Processual da UERJ

Patrono: José Carlos Barbosa Moreira. ISSN 1982-7636. pp. 664-683 http://www.e-publicacoes.uerj.br/index.php/redp/index

A elaboração de um novo código tem sempre como justificativa uma renovação do direito que já não é mais passível de ser feita apenas por meio de emendas. Muitos temas, tanto antigas mazelas, quanto novas tendências não recepcionadas pelo código anterior, foram postas em pauta na discussão do projeto do NCPC. A flexibilização do procedimento, como mecanismo de adequação do processo às situações fáticas de um conflito, é um tema que tem sido discutido de diferentes formas e em diferentes países, a exemplo de Portugal e Inglaterra, e mais recentemente no Brasil. Em que pese tenha se mantido o sistema de normas minuciosas responsável por descrever o rito processual de maneira detalhada, os arts. 190 e 191, do NCPC, são dispositivos que intentam excetuar uma estrita e irrefletida realização de atos processuais positivados frente às necessidades suscitadas em um caso concreto.

Nota-se que a flexibilização foi tratada de forma diversa nas diferentes fases do processo legislativo de criação do NCPC. Inicialmente, no Anteprojeto apresentado pela Comissão de Juristas foi apresentada a chamada "flexibilização procedimental legal genérica", atribuindo ao juiz o papel de perceber e adaptar o processo diante das especificidades do caso concreto. No Senado Federal - a Casa iniciadora -, a matéria da flexibilização, alvo de muitas críticas, foi restrita à dilatação de prazos processuais e alteração da ordem de produção de prova. Na Câmara dos Deputadas - a Casa revisora -, houve uma inovação no sentido de ampliar a participação das partes na condução do processo a partir da chamada "flexibilização voluntária das regras de procedimento". A flexibilização no Novo CPC alinha-se a este último posicionamento.

Frente à heterogeneidade de tratamento do instituto da flexibilização procedimental, esta pesquisa procurou abordar como tal tema, que vem adquirindo grande importância na processualística brasileira, foi tratado nas duas casas legislativas do país durante a elaboração da lei que irá trazer uma renovação substancial ao processo civil brasileiro.

\section{REFERÊNCIAS BIBLIOGRÁFICAS}

COSTA, Alexandre Araújo. Introdução ao direito: uma perspectiva zetética das ciências jurídicas. Porto Alegre : Sergio Antonio Fabris Editor, 2001.

COSTA, Henrique Araújo. Os poderes do juiz na Inglaterra e no Brasil: estudo comparado sobre os case management powers. Tese de doutorado em direito, PUC/SP, 2012.

DINAMARCO, Cândido Rangel. A instrumentalidade do processo. 15 ed. São Paulo: Malheiros Ed., 2013. 
Revista Eletrônica de Direito Processual - REDP. Volume 16. Julho a dezembro de 2015

Periódico Semestral da Pós-Graduação Stricto Sensu em Direito Processual da UERJ

Patrono: José Carlos Barbosa Moreira. ISSN 1982-7636. pp. 664-683 http://www.e-publicacoes.uerj.br/index.php/redp/index

DIDIER JR., Fredie. Sobre dois importantes, e esquecidos, principios do processo: adequação e adaptabilidade do procedimento. Disponível em: $<$ http://www.mundojuridico.adv.br/cgi-bin/upload/texto073.doc $>$. Acesso em 12 de out. 2014.

GAJARDONI, Fernando da Fonseca. A flexibilização do procedimento processual no âmbito da “common law”. Revista de Processo, São Paulo, v. 163, abr. 2008.

GAJARDONI, Fernando da Fonseca. Flexibilidade procedimental: um novo enfoque para o estudo do procedimento em matéria processual. Tese de doutorado em Direito. USP/São Paulo, 2006.

GAJARDONI, Fernando da Fonseca. Procedimentos, déficit procedimental e flexibilização procedimental no novo CPC. Revista de informação legislativa, v. 48, n. 190 t.1, abr./jun. 2011, p. 163-177.

LIEBMAN, Enrico Tullio. Manual de direito processual civil. Volume 1. 2 ed. Tradução e notas de Cândido Rangel Dinamarco. Rio de Janeiro, 1985.

MARINONI, Luiz Guilherme. Teoria geral do processo. Volume 1.8 ed. São Paulo: Revista dos tribunais, 2014.

MITIDIERO, Daniel \& OLIVEIRA, Alvaro de. Curso de processo civil: teoria geral do processo civil e parte geral do direito processual civil. Volume 1. 2 ed. São Paulo: Atlas, 2012.

MOREIRA, José Carlos Barbosa. O novo processo civil brasileiro: exposição sistemática do procedimento. 29 ed. Rio de Janeiro: Forense, 2012.

OLIVEIRA, Carlos Alberto Alvaro de. Do formalismo no processo civil. 4 ed. São Paulo: Saraiva, 2010. 